\title{
One-tube restriction enzyme digest and fluorescent labeling for restriction endonuclease fingerprinting single-strand conformational polymorphism
}

\author{
Ove Bruland ${ }^{1}$ and Per Morten Knappskog ${ }^{1,2}$ \\ ${ }^{1}$ Haukeland University Hospital, Bergen, and ${ }^{2}$ University of Bergen, Bergen, Norway
}

BioTechniques 37:906-912 (December 2004)

Single-stranded conformational polymorphism (SSCP) has been widely used for detecting mutations and single nucleotide polymorphisms (SNPs) since the method was first described in 1989 by Orita et al. $(1,2)$. Although the original protocol has been optimized with respect to running conditions and gel composition $(3,4)$, the major drawbacks of this method have been the limited fragment length that can be separated on a standard polyacrylamide slab gel and the simultaneous detection of weak and strong radioactively labeled conformers. This has been partly overcome by restriction endonuclease fingerprinting single-strand conformational polymorphism (REFSSCP; Reference 5), in which large radioactively labeled PCR fragments are digested by restriction enzymes before separation on polyacrylamide slab gels. Fluorescence SSCP (6), with separation and detection performed on DNA sequencers, both enhanced the sensitivity and reproducibility of the method $(7,8)$. In addition, SSCP has been successfully adapted to capillary electrophoresis (9-11). Fluorescence labeling and detection make it possible to add an internal size standard to correct for lane-to-lane or run-to-run variations. There are several different approaches to the fluorescence labeling of the PCR fragments, including prelabeling of PCR primers (6), incorporation of fluorescently labeled nucleotides $(12,13)$, and multicolor post-labeling of the PCR products (14). With fluorescence labeling and detection using SSCP analysis, it is important that all products are uniformly labeled and that the labeled nucleotide is present at the end of the PCR product and not randomly distributed within the PCR product. We have designed a fluorescence REF-SSCP protocol for mutation or SNP detection by combining widely used technologies (i.e., restriction digest, DNA minisequencing, and SSCP analysis) and have tested it by performing a blind test on a collection of mutated cDNAs of human phenylalanine hydroxylase (PAH). When performing the blind test, we detected gel shifts in all mutated samples. Following PCR amplification, the PCR product (1544 bp) was digested with two restriction enzymes (HinfI and BanI), producing DNA fragments with $5^{\prime}$ protruding overhangs ranging from 291 to $20 \mathrm{bp}(291,230,206$, 199, 174, 111, 99, 95, 66, 51, and 22 bp; Figure 1A). The $5^{\prime}$ protruding overhang is essential for the next step, labeling by minisequencing of each digested fragment by including Thermo Sequenase $^{\mathrm{TM}}$ (Amersham Biosciences AB, Uppsala, Sweden) and fluorescence-labeled ddNTPs. The restriction enzyme digest and the minisequencing are performed simultaneously in one tube. Because only fluorescencelabeled ddNTPs are present, only one fluorescence-labeled ddNTP will be incorporated at the end of each digested DNA fragment in a sequence-dependent manner. The blind test comprised one no-template control (no DNA) and 39 cDNAs (cloned and sequence verified) of human PAH. Within the 39 cDNA samples, 36 contained one or more specific mutations while 3 samples were normal controls (no sequence variants). The mutated samples were chosen to represent sequence variants distributed throughout the PAH cDNA (Figure 1A). One normal control was added as a reference of known identity against which each of the 40 samples was compared. The cDNAs were PCR amplified from pMAL-PAH (15) with 2 ng plasmid DNA, $5 \mu \mathrm{L}$ GeneAmp ${ }^{\circledR}$ $10 \times$ PCR buffer (Applied Biosystems, Foster City, CA, USA), $4 \mu \mathrm{L} 25 \mathrm{mM}$ $\mathrm{MgCl}_{2}, 1 \mu \mathrm{L} 10 \mu \mathrm{M}$ forward primer (5'GGTCGTCAGACTGTCGATGA-3'), $1 \mu \mathrm{L} 10 \mu \mathrm{M}$ reverse primer (5'-TTTTCGGACTTTTTCTGATG-3'), $0.2 \mu \mathrm{L}$ $25 \mathrm{mM}$ dNTP, and $2.5 \mathrm{U}^{\text {AmpliTaq }}{ }^{\circledR}$ polymerase (Applied Biosystems) in a final volume of $50 \mu \mathrm{L}$. The PCR parameters were 20 cycles for $94^{\circ} \mathrm{C}$ for $5 \mathrm{~min}$, $94^{\circ} \mathrm{C}$ for $20 \mathrm{~s}, 58^{\circ} \mathrm{C}$ for $20 \mathrm{~s}$, and $72^{\circ} \mathrm{C}$ for $10 \mathrm{~s}$, followed by a final extension at $72^{\circ} \mathrm{C}$ for $4 \mathrm{~min}$. The PCR products were then purified on QIAquick ${ }^{\circledR}$ PCR purification columns (Qiagen $\mathrm{GmbH}$, Hilden, Germany), as described by the manufacturer. For fragmentation and labeling, $0.5-5.0 \mathrm{ng}(1 \mu \mathrm{L})$ purified PCR product were digested in a total volume of $30 \mu \mathrm{L}$, containing $3 \mu \mathrm{L} 10 \times$ restriction enzyme buffer (HinfI bf, 2 U HinfI, 2 U BanI, NEBuffer 2; all from New England Biolabs, Beverly, MA, USA), 1 U Thermo Sequenase, and $0.1 \mu \mathrm{L}$ fluorescent labeled ddNTPs $(0.05 \mu \mathrm{L}$ each of R6G-labeled ddATP DyeDeoxy and R110-labeled ddGTP DyeDeoxy Terminators; Applied Biosystems). The reaction was incubated at $37^{\circ} \mathrm{C}$ for $3 \mathrm{~h}$. Excess ddNTPs were removed by purification on QIAquick PCR purification columns (Qiagen). For SSCP analysis, the labeled DNA fragments were vacuumed dried and dissolved in $3 \mu \mathrm{L}$ formamide/ Blue Dextran 2000 (Pharmacia Fine Chemicals, Uppsala, Sweden), $2 \mu \mathrm{L}$ GENESCAN $^{\circledR}-500$ ROX standard (Applied Biosystems), and $0.5 \mu \mathrm{L}$ $0.1 \mathrm{M} \mathrm{NaOH}$. Before loading the samples onto the polyacrylamide slab gel $[10 \%$ urea, $6 \%$ polyacrylamide gel, $1 \%(w / v)$ bisacrylamide/19\% (w/ v) acrylamide, $1 \times$ TBE (Tris-borateEDTA)], they were denatured at $98^{\circ} \mathrm{C}$ for $3 \mathrm{~min}$ and immediately cooled on ice. Each sample $(1.5 \mu \mathrm{L})$ was loaded and separated on an ABI PRISM ${ }^{\circledR} 377$ DNA Sequencer (Applied Biosystems) at 2140 volts $(\mathrm{V}), 60 \mathrm{~mA}$, and $200 \mathrm{~W}$ in $1 \times$ TBE for $6 \mathrm{~h}$. The temperature was kept constant at $12^{\circ} \mathrm{C}$ by an external 
water bath. Fragment lengths of each individual conformer were determined by comparing the data point to that of the internal GENESCAN-500 ROX standard using the GENESCAN v.3.0 software (Applied Biosystems; Figure 2C). Any abbreviations in fragment length (shift) to that of the normal control sample were determined, resulting in all the mutated samples being detected and the three normal samples identified. Introducing more than one restriction enzyme enabled multicolor labeling and localization of specific restriction fragments containing sequence variants (Figure 2, $\mathrm{A}$ and $\mathrm{B}$ ), depending on the recognition sequence and digestion of the particular restriction enzymes. We have successfully tested the protocol for SNP haplotyping of selected families, in which a $5.1-\mathrm{kb}$ genomic DNA fragment of the human hydroxymethylbilane synthase $(H M B S)$ gene was screened for SNPs, with restriction enzyme fragment sizes from 600 to $20 \mathrm{bp}$. The shifts discovered were then used directly as intragenic markers for haplotyping (16).

The one-tube restriction enzyme digest and fluorescent ddNTP labeling of $5^{\prime}$ protruding ends created by restriction enzymes (Figure 1B) proved to be highly efficient, reliable, and costefficient. It is not time-consuming, the concentration of fluorescent ddNTPs required is very low $(0.05 \mu \mathrm{L} /$ sample $)$, and all fragments were reproducibly and uniformly labeled (Figure 2A). We believe that the ability to investigate large PCR fragments makes this method suitable for investigating SNPs located in genomic DNA, without requiring any knowledge of existing SNPs in the region or their frequencies. We therefore propose that this protocol

\section{A)}

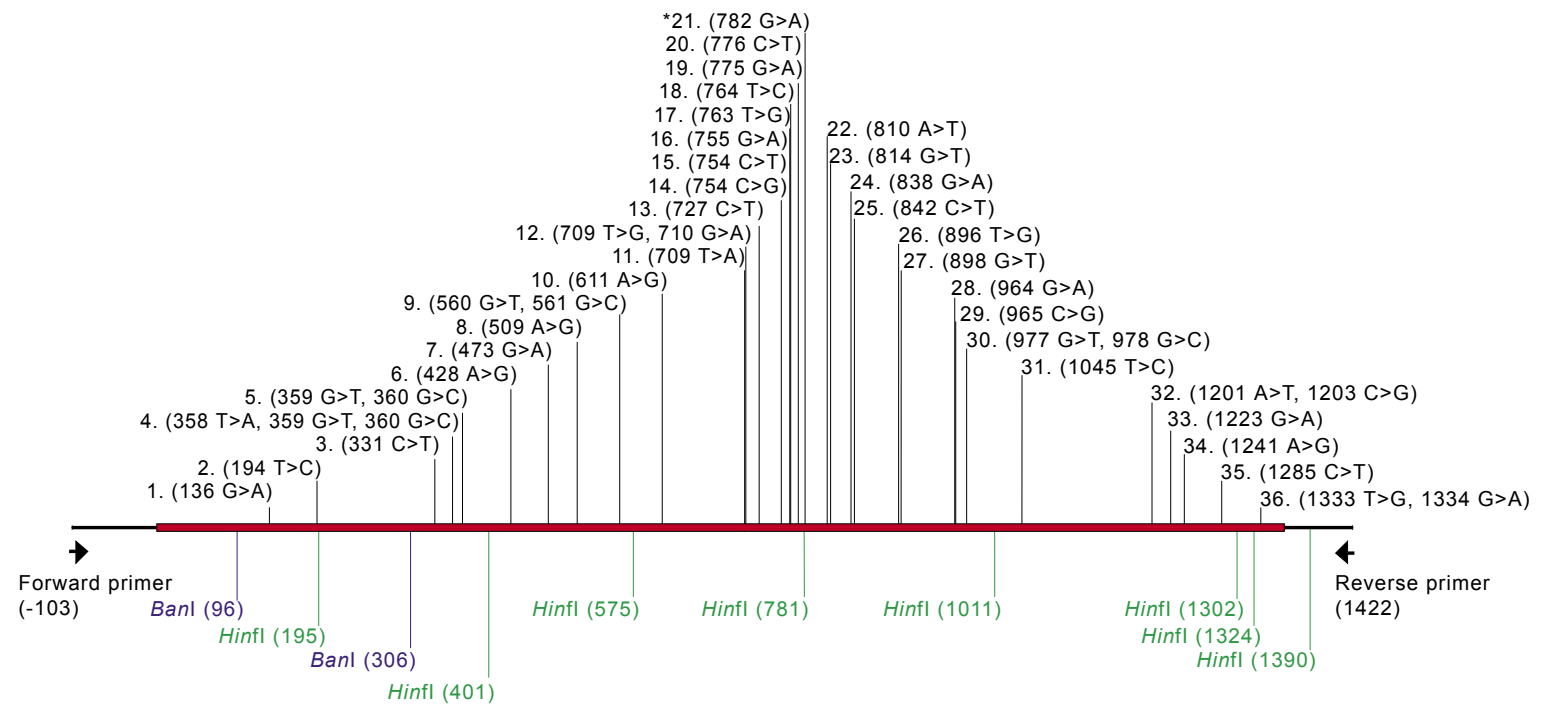

B)

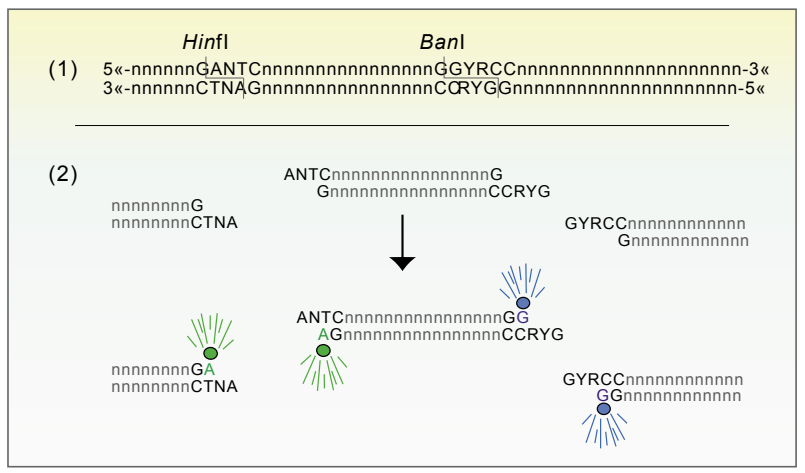

Figure 1. Overview of PAH cDNA samples and the fluorescence labeling step. (A) Identity and distribution of mutations in PAH cDNA samples included in the blind test. Each sample is numbered from 1 to 36 and represented by position and the specific mutation(s). No sample had mutations in more than one codon. The red line indicates the PAH coding sequence, the black line is the pMAL-E vector sequence. Numbering is according to the cDNA sequence of PAH (starting at the first ATG, GenBank ${ }^{\circledR}$ accession no. NM 000277). The location and identity of the restriction enzyme sites are marked below the red line. $* 21$. (782 G > A) is the only sample in which the mutation disrupts a restriction enzyme site (HinfI 781), creating a restriction fragment length polymorphism (RFLP). None of the sequence variants creates additional HinfI or BanI sites. (B) Outlining the one-tube digestion and labeling by minisequencing. (1) Deoxy nucleotides from PCR must be removed by purifying the PCR product before (2) digestion and labeling, which are performed simultaneously in one tube Because only fluorescent ddNTPs are present, only one single nucleotide will be incorporated in a sequence-dependent manner at the end of each digested fragment. PAH, phenylalanine hydroxylase. 
A)

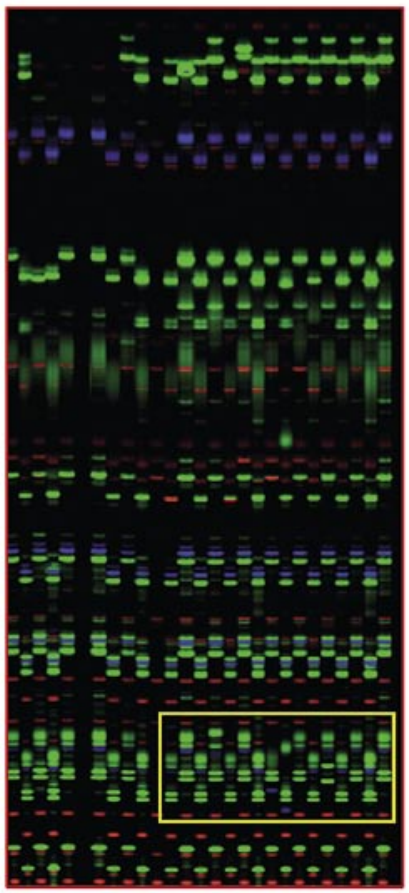

B)

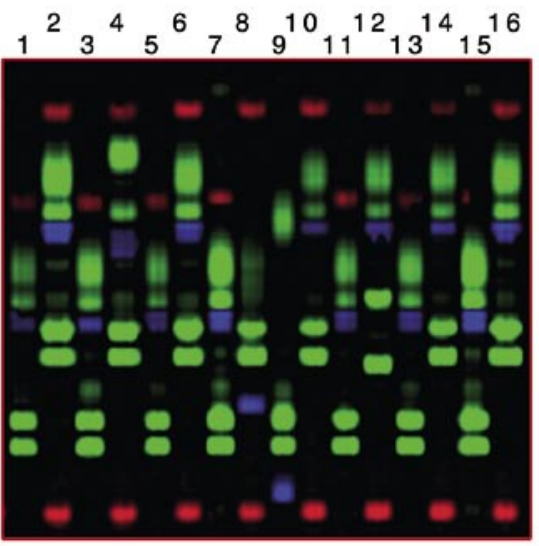

C)
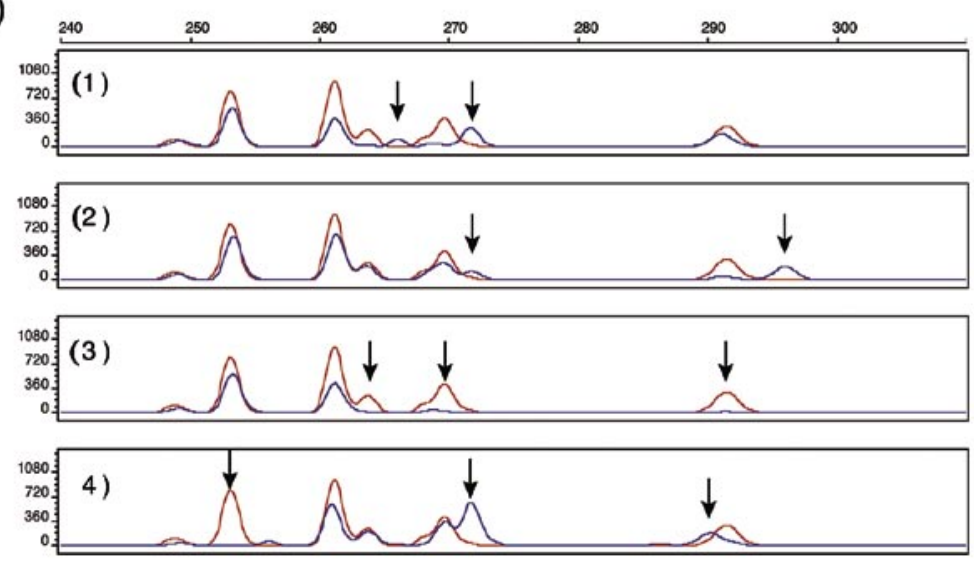

Figure 2. Fluorescence REF-SSCP of PAH cDNA samples. (A) Gel image with 26 samples showing all labeled fragments, ROX-500 standard in red, HinfI-digested ends in green (labeled with R6G-labeled ddATP), and BanI-digested ends in blue (labeled with R110-labeled ddGTP). The direction of electrophoresis is from top to bottom. Half of the samples were loaded onto the gel in every second well (2, 4, 6-26) and subjected to electrophoresis for 1 min before loading the rest of the samples $(1,3,5-25)$. Two lanes contained ROX-labeled DNA standard only (lanes 5 and 10). Shifts are readily visible in most sections of the gel image correlating to the specific location of each specific sequence variant. A yellow box indicates a section of the gel image (enlarged in panel B) showing co-migration of two individual fragments, BanI(306)-HinfI(401) and HinfI(1324)-HinfI(1390). Three of the 16 samples displayed were mutated within the double-labeled fragment (HinfI-BanI), as shown in lane $4(331 \mathrm{C}>\mathrm{T})$; lane $8(358$ $\mathrm{T}>\mathrm{A}, 359 \mathrm{G}>\mathrm{T}, 360 \mathrm{G}>\mathrm{C})$; and lane $9(359 \mathrm{G}>\mathrm{T}, 360 \mathrm{G}>\mathrm{C})$. One sample with a mutation in the single-labeled (HinfI-HinfI) fragment is shown in lane $12(1333 \mathrm{~T}>\mathrm{G}, 1334 \mathrm{G}>\mathrm{A})$. The other samples shown here carried no mutations in this particular region: (1) $1241 \mathrm{~A}>\mathrm{G}$; (2) $611 \mathrm{~A}>\mathrm{G}$; (3) $1285 \mathrm{C}>\mathrm{T}$; (5) $709 \mathrm{~T}>\mathrm{G}, 710 \mathrm{G}>\mathrm{A}$; (6) $709 \mathrm{~T}>\mathrm{A}$; (7) normal sample; (10) $560 \mathrm{G}>\mathrm{T}, 561 \mathrm{G}>\mathrm{C}$; (11) $977 \mathrm{G}>\mathrm{T}$, $978 \mathrm{G}>\mathrm{C}$; (13) normal sample. Lanes 14-15 were the reference samples. (C) To avoid lane-to-lane and run-to-run variations, analyzing shifts were done by comparing chromatograms to that of the reference samples after normalizing each individual sample to the internal size standard. Here we show four samples, (1) $776 \mathrm{C}>\mathrm{T}$; (2) $810 \mathrm{~A}>\mathrm{T}$; (3) $814 \mathrm{G}>\mathrm{T}$; and (4) $964 \mathrm{G}>\mathrm{A}$, carrying mutations in the region or restriction enzyme fragments displayed in this chromatogram. The red line represents the R6G-labeled normal reference, and blue line represents four of the R6G-labeled mutant samples displaying shifts in this particular region. REF-SSCP, restriction endonuclease fingerprinting single-strand conformational polymorphism; PAH, phenylalanine hydroxylase. should be useful for investigating sequence variants in model organisms as well as nonmodel organisms, in which sequence data and database information of SNPs are limited.

\section{COMPETING INTERESTS STATEMENT}

The authors declare no competing interests.

\section{REFERENCES}

1.Orita, M., H. Iwahana, H. Kanazawa, K. Hayashi, and T. Sekiya. 1989. Detection of polymorphisms of human DNA by gel electrophoresis as single-strand conformation polymorphisms. Proc. Natl. Acad. Sci. USA 86:2766-2770.

2.Orita, M., Y. Suzuki, T. Sekiya, and K. Hayashi. 1989. Rapid and sensitive detection of point mutations and DNA polymorphisms using the polymerase chain reaction. Genomics 5:874-879.

3.Glavac, D. and M. Dean. 1993. Optimization of the single-strand conformation polymorphism (SSCP) technique for detection of point mutations. Hum. Mutat. 2:404-414.

4.Yip, S.P., D.A. Hopkinson, and D.B. Whitehouse. 1999. Improvement of SSCP-analysis by use of denaturants. BioTechniques 27:2024.

5.Lovlie, R. and H.G. Eiken. 1997. Increased ${ }^{32} \mathrm{P}-\mathrm{SSCP}$ sensitivity by combining RE digestion and extended X-ray film exposures. BioTechniques 22:598-602.

6.Makino, R., H. Yazyu, Y. Kishimoto, T. Sekiya, and K. Hayashi. 1992. F-SSCP: fluorescence-based polymerase chain reactionsingle-strand conformation polymorphism (PCR-SSCP) analysis. PCR Methods Appl. 2:10-13.

7.Moore, L., T. Godfrey, C. Eng, A. Smith, R. Ho, and F.M. Waldman. 2000. Validation of fluorescent SSCP-analysis for sensitive detection of p53 mutations. BioTechniques 28:986992.

8.Hayashi, K. 1999. Recent enhancements in SSCP. Genet. Anal. 14:193-196.

9.Larsen, L.A., M. Christiansen, J. Vuust, and P.S. Andersen. 1999. High-throughput single-strand conformation polymorphism analysis by automated capillary electrophoresis: robust multiplex analysis and patternbased identification of allelic variants. Hum. Mutat. 13:318-327.

10.Hayashi, K., H.M. Wenz, M. Inazuka, T. Tahira, T. Sasaki, and D.H. Atha. 2001. SSCP-analysis of point mutations by multicolor capillary electrophoresis. Methods Mol. Biol. 163:109-126.

11.Sasaki, T., T. Tahira, A. Suzuki, K. Higasa, Y. Kukita, S. Baba, and K. Hayashi. 2001. Precise estimation of allele frequencies of single-nucleotide polymorphisms by a quantitative SSCP-analysis of pooled DNA. Am. J. 
Hum. Genet. 68:214-218.

12.Iwahana, H., M. Fujimura, Y. Takahashi, T. Iwabuchi, K. Yoshimoto, and M. Itakura. 1996. Multiple fluorescence-based PCR-SSCP-analysis using internal fluorescent labeling of PCR products. BioTechniques 21:510-519.

13.Syvanen, A.C., K. Aalto-Setala, L. Harju, K. Kontula, and H. Soderlund. 1990. A primer-guided nucleotide incorporation assay in the genotyping of apolipoprotein $\mathrm{E}$. Genomics 8:684-692.

14.Inazuka, M., T. Tahira, and K. Hayashi. 1996. One-tube post-PCR fluorescent labeling of DNA fragments. Genome Res. 6:551-557.

15.Knappskog, P.M., H.G. Eiken, A. Martinez, O. Bruland, J. Apold, and T. Flatmark. 1996. PKU mutation (D143G) associated with an apparent high residual enzyme activity: expression of a kinetic variant form of phenylalanine hydroxylase in three different systems. Hum. Mutat. 8:236-246.

16.Tjensvoll, K., O. Bruland, Y. Floderus, $\mathbf{O}$. Skadberg, S. Sandberg, and J. Apold. 2003. Haplotype analysis of Norwegian and Swedish patients with acute intermittent porphyria (AIP): extreme haplotype heterogeneity for the mutation R116W. Dis. Markers 19:41-46.

Received 13 May 2004; accepted 15 July 2004.

Address correspondence to Ove Bruland, Center of Medical Genetics and Molecular Medicine, Haukeland University Hospital, N-5021 Bergen, Norway. e-mail: ove.bruland@helse-bergen.no

\section{Rapid functional cloning of cell adhesion molecules}

Christiane Ruedl, Monika Bauer, Roger R. Beerli, Ute Lässing, Klaus Dietmeier, Lidia Ivanova, Lorenz Vogt, Philippe Saudan, and Martin F. Bachmann

Cytos Biotechnology AG, Zürich, Switzerland

BioTechniques 37:912-916 (December 2004)

Cell adhesion molecules (CAMs) regulate a variety of processes in the body, including tissue organization and maintenance, cellular activation, and migration. Many CAMs are therefore also involved in pathological conditions, such as metastasis formation, inflammatory processes, and autoimmune diseases, just to name a few. A large number of CAMs that are potentially relevant for pharmaceutical intervention have been described (1), and their binding partners have been identified. Yet it would be desirable to have methods for the identification of CAMs involved in the interaction between two individual cell types. Particularly useful would be a technology that does not require a priori information other than which specific cell types should be studied. In order to develop such a method, we made use of (i) Sindbis virus-based cDNA expression libraries (2) and (ii) the observation that two cells interacting with each other through CAMs form stable cell dimers that may be separated from single cells using flow cytometry (FCM). As a model system, we tried to identify molecules involved in the interaction of dendritic cells (DCs), the major antigen-presenting cell of the immune system, and lymphocytes. In the first step, a Sindbis virus-based expression library was generated from the cDNA of murine ex vivo isolated DCs. As previously described (2), such viral libraries are replication competent, and each virus contains the genetic information for one protein. To ensure the representation of large genes, three individual size-fractionated sublibraries were generated (Figure 1A). The total library had a size of $3.5 \times 10^{7}$ primary clones, of which $7 \times 10^{6}$ clones had an insert size of larger than $3 \mathrm{~kb}$ (Figure 1B). The cDNA library was converted into a viral library (2) and baby hamster kidney (BHK) cells were infected with the recombinant Sindbis viruses at a multiplicity of infection of 0.1 . This procedure ensures that not more than one virus-derived gene is expressed per infected BHK cell (2). Six hours after infection, BHK cells were mixed with ex vivo isolated murine lymphocytes (at a ratio of 10:1), centrifuged at $230 \times$ $g$ for $1 \mathrm{~min}$, and gently resuspended. It has previously been shown that this procedure allows the formation of stable conjugates between DCs and specific T cells $(3,4)$. To facilitate the detection of cellular conjugates containing one BHK cell and a lymphocyte, we labeled the lymphocytes with a green fluorescent dye [5-,6-carboxyfluorescein diacetate succinimidyl ester (CFSE)] according to standard protocols (5). Thus, if analyzed by FCM, dimers appear as green fluorescent cells exhibiting a large forward scatter (Figure 1C). Cell conjugates were sorted into 24-well plates containing a monolayer of BHK cells to allow for viral replication. Two days later, the infected BHK cells were incubated again with CFSE-labeled lymphocytes (at a ratio of 1:1), and the formation of cellular conjugates was assessed by FCM (Figure 2A). For wells that were positive in the rescreen, RNA was isolated from infected BHK cells, and genes encoded were amplified by PCR. This led to the identification of several genes, including splice 